\title{
Pharmacokinetics, excretion and metabolites analysis of DL0410, a dual-acting cholinesterase inhibitor and histamine-3 receptor antagonist
}

\author{
XIAOCONG PANG $^{1}$, YING ZHAO ${ }^{1}$, JUNKE SONG $^{1}$, DE KANG $^{1}$, \\ SONG WU ${ }^{1}$, LIN WANG ${ }^{1}$, AILIN LIU ${ }^{1,2}$ and GUANHUA DU ${ }^{1,2}$ \\ ${ }^{1}$ State Key Laboratory of Bioactive Substance and Function of Natural Medicines, \\ Institute of Materia Medica; ${ }^{2}$ Beijing Key Laboratory of Drug Target and Screening Research, \\ Chinese Academy of Medical Sciences and Peking Union Medical College, Beijing 100050, P.R. China
}

Received December 15, 2017; Accepted May 4, 2019

DOI: $10.3892 / \mathrm{mmr} .2019 .10306$

\begin{abstract}
DL0410, a dual-action cholinesterase inhibitor and histamine-3 receptor antagonist with a novel structural scaffold, may be a potential candidate for the treatment of Alzheimer's disease (AD). To the best of the authors' knowledge, this is the first study to demonstrate a reliable method for the measurement of DL0410 in rat plasma, brain, bile, urine and feces samples, and identification of its primary metabolites. The pharmacokinetic properties of DL0410 were analyzed by liquid chromatography-mass spectrometry at oral doses of 25,50 and $100 \mathrm{mg} / \mathrm{kg}$ and intravenous dose of $5 \mathrm{mg} / \mathrm{kg}$. The investigation of the excretion and metabolism of DL0410 was determined following liquid-liquid extraction for biliary, urinary and fecal samples. Finally, the cytochrome (CY)P450 isoforms involved in the production of DL0410 metabolites with recombinant human cytochrome P450 enzymes were characterized. The results suggested that DL0410 was not well absorbed; however, was distributed to the entorhinal cortex and hippocampus of the brain. A total of two common metabolites of the reduction of DL0140 in the bile, urine and feces were identified and CYP2D6 was involved in this reaction. The pharmacokinetic results of DL0410 provided information for the illustration of its pharmacodynamic properties, mechanism of action and promoted its continued evaluation as a therapeutic agent for AD treatment.
\end{abstract}

Correspondence to: Professor Ailin Liu or Professor Guanhua Du, Beijing Key Laboratory of Drug Target and Screening Research, Chinese Academy of Medical Sciences and Peking Union Medical College, 1 Xian Nong Tan Street, Beijing 100050, P.R. China

E-mail: liuailin@imm.ac.cn

E-mail:dugh@imm.ac.cn

Key words: Alzheimer's disease, cholinesterase inhibitor, histamine-3 receptor antagonist, DL0410, liquid chromatographymass spectrometry

\section{Introduction}

Alzheimer's disease (AD) is the most common neurodegenerative cause of dementia and it is a progressive neurodegenerative disorder of the central nervous system, which leads to significant individual morbidity, mortality and economic impact on the health care system $(1,2)$. AD may be characterized by a marked dsyregulation of the cholinergic system, together with other neurotransmitter systems (including glutamate and serotonin). Acetylcholinesterase (AChE) inhibitors donepezil, galantamine along with rivastigmine and the N-methyl-D-aspartate antagonist memantine are examples of the current standard treatments, which do not inhibit the progression of $\mathrm{AD}$ and offer marginal therapeutic advantages (3). Even though novel therapeutic methods have appeared in recent years, there have been poor clinical results, which makes cholinesterase inhibitors the primary approach for AD treatment (3-5). The acetylcholine (Ach) signaling pathway is additionally inhibited through the action of AChE (ExPASy enzyme entry no. E.C. 3.1.1.7) as well as butyrylcholinesterase (BChE; ExPASy enzyme entry no. E.C. 3.1.1.8) (6-8), which regulates the levels of ACh by hydrolysis (4). Controlled inhibition of brain AChE and BChE may slow neurodegeneration in $\mathrm{AD}$ (9-13).

The concentration of choline may be increased through $\mathrm{AChE}$ in addition to $\mathrm{BChE}$ inhibition, by the application of the [1,1'-([1,1'-biphenyl]-4,4'-diyl)bis(3-(piperidin-1-yl) propan-1-one) dihydrochloride; DL0410]-. DL0410 had been selected from $>100,000$ compounds using high-throughput screening assays for AChE in addition to BChE inhibitors (14). Subsequently, the in vitro ability of DL0410 to inhibit $\mathrm{AChE}$ and $\mathrm{BChE}$ was determined with half maximal inhibitory concentration $\left(\mathrm{IC}_{50}\right.$ ) values of $0.286 \pm 0.004$ and $3.962 \pm 0.099 \mu \mathrm{mol} / 1$, respectively, which are comparable with the donepezil as well as rivastigmine (15). The authors' previous study demonstrated that DL0410 binds to the active-site groove of AChE (16), whereas other previous studies (14-18) confirmed its efficacy and safety. Additionally, DL0410 was able to inhibit histamine receptor $3\left(\mathrm{H}_{3} \mathrm{R}\right)$ with $\mathrm{IC}_{50}$ values of $0.308 \pm 0.003 \mu \mathrm{mol} / 1 . \mathrm{H}_{3} \mathrm{Rs}$ function as regulators that modulate the release of ACh, dopamine, serotonin 
and norepinephrine (19). Consequently, $\mathrm{H}_{3} \mathrm{R}$ antagonists have potential as a treatment for AD (19-22). It was additionally demonstrated that DL0410 has the ability to improve memory deficits in APP/PS1 transgenic mice and $A \beta_{1-42}$-induced amnesia in mice (15). Cholinesterase inhibition, $A \beta$ plaque inhibition, in addition to enhancement of synapse loss through the regulation of synapse-associated protein expression may serve an important role in beneficial effects of DL0410. As a result, DL0410 as multi-target-directed ligand may be considered as a candidate drug for AD treatment (23).

In the present study, a sensitive, reproducible and practical method was developed and used for the determination of the pharmacokinetic properties of DL0410 in Sprague-Dawley (SD) rat plasma and brain tissue for the first time. In addition, this is the first study to the best of the authors the knowledge to investigate the dose proportionality and bioavailability of DL0410. The excretion of DL0410 was determined by liquid chromatography-mass spectrometry (LC-MS) following liquid-liquid extraction for biliary, urinary and fecal samples. Furthermore, ultra-high performance liquid chromatography-quadrupole time-of-flight mass spectrometry (UPLC-Q-TOF/MS) with electrospray ionization (ESI) were additionally applied to identify the primary metabolites of DL0410 in rat bile, urine and feces. The present study aimed to provide preclinical pharmacokinetic information regarding DL0410 and lay a foundation for evaluating the clinical efficiency of DL0410 for oral administration.

\section{Materials and methods}

Reagents. DL0410 (purity >99\%) was synthesized by the Institute of the Materia Medica, Chinese Academy of Medical Sciences (Beijing, China). Phenacetin (internal standard; IS) was obtained from the National Institutes for Food and Drug Control (Beijing, China). Acetonitrile $\left(\mathrm{ACN} ; \mathrm{CH}_{3} \mathrm{CN}\right.$; LC-MS-grade) and methanol (MeOH; LC-MS grade) were purchased from J.T. Baker; Thermo Fisher Scientific, Inc., (Waltham, MA, USA). Formicacid [HCOOH; high (H)PLC-grade] was obtained from Tedia (Fairfield, CT, USA). Recombinant CYP450s (CYP1A2, CYP2C9, CYP2D6 and CYP3A4) were obtained from Corning Life Sciences (Tewksbury, MA, USA). Potassium phosphate buffer (pH 7.4) was purchased from Beijing Solarbio Science \& Technology Co., Ltd. (Beijing, China). Ethyl acetate (EtOAc) was purchased from Sinopharm Chemical Reagent Co., Ltd. (Shanghai, China). Anticoagulation tubes with heparin were obtained from Jiangsu Kangjian Healthcare Co., Ltd., (Taizhou, China). Pure water was purchased from the Hangzhou Wahaha Company (Hangzhou, China), with all other chemical reagents being of analytical grade level or higher.

Experimental animals. A total of 90 rats were supplied by Beijing HFK Bioscience Co., Ltd. (Beijing, China; cat. no. SCXK 2014-0004). All experimental protocols involving 45 male and 45 female Sprague-Dawley (SD) rats of 6-8 weeks old (210-230 g) were reviewed and approved by the animal experimentation center of the Institute of Materia Medica, Chinese Academy of Medical Sciences (Beijing, China). The animals were allowed to acclimatize in the animal facilities for $\sim 7$ days following arrival, complete with air conditioning and an automatically controlled photoperiod of $12 \mathrm{~h}$ of daylight. The temperature of the rearing room was maintained at $20-24^{\circ} \mathrm{C}$ and the relative humidity was $50-65 \%$. Animals were given free access to food and water for these $12 \mathrm{~h}$ prior to being used in the experiments, during this time only the food was removed.

High performance LC-MS for plasma, brain, bile, urine and fecal samples. The Agilent 1200 liquid chromatography-6100 mass spectrometer (Agilent Technologies, Inc., Santa Clara, CA, USA) was employed for the detection of DL0410 and phenacetin (IS). The analytical column was Agilent Zorbax SB-C18 (100x2.1 mm; $3.5 \mu \mathrm{m}$; Agilent Technologies, Inc.). The mobile phase was composed of methanol-ACN-water (0.5\% formic acid; 15:10:75, v/v) for plasma and brain samples, and (15:9:76, v/v) for bile, urine, and fecal samples. The injection volume was $10 \mu \mathrm{l}$ and the flow rate was $0.3 \mathrm{ml} / \mathrm{min}$. The column temperature was maintained at $35^{\circ} \mathrm{C}$ and the mass spectrometer was used in the positive scan mode. The conditions of ESI source were as follows: Drying gas flow was set at $10 \mathrm{l} / \mathrm{min}$, drying gas temperature was $350^{\circ} \mathrm{C}$, nebulizer pressure was 35.0 pounds per square inch gauge and capillary voltage was 3,000 V. The ESI was conducted using nitrogen to assist nebulization. The typical compound parameters, fragmentor voltage and gain value, were set at $90 \mathrm{~V}$ and 1.5, respectively. The MS detector was operated in selective ion monitoring mode using the quantification ions $[\mathrm{M}+\mathrm{H}]^{+}$at $\mathrm{m} / \mathrm{z}$ 217.15 for DL0410 and m/z 180.22 for IS.

UPLC-Q-TOF-MS for metabolite identification. Bile, urine and fecal metabolites were analyzed by UPLC-Q-TOF-MS (XEVO G2; Waters Corporation, Milford, MA, USA) with an Agilent Zorbax SB-C18 (100x2.1 mm; $3.5 \mu \mathrm{m})$ by gradient elution using $0.2 \%$ formic acid in $\mathrm{ACN}(\mathrm{A})$ and $0.2 \%$ formic acid in water $(\mathrm{B})$ at a flow rate of $0.4 \mathrm{ml} / \mathrm{min}$. The gradient profile was as follows: 0-2 $\min (\mathrm{A}, 5 \%), 2-12 \mathrm{~min}(\mathrm{~A}, 2-20 \%)$, 12-14 min (A, 20-30\%), 14-18 min (A, 30-100\%), 18-21 min (A, 100\%), 21-21.10 min (A, 100-5\%) and 21-25 min (A, 5\%), and was held for $2.5 \mathrm{~min}$ for the following run. The injection volume was $10 \mu \mathrm{l}$ and the temperature of the column oven was set to $35^{\circ} \mathrm{C}$. Ionization was performed in the positive ESI mode. For MS detection, the optimum ESI conditions were as follows: Source temperature of $100^{\circ} \mathrm{C}$, desolvation temperature of $300^{\circ} \mathrm{C}$, desolvation gas flow of $900 \mathrm{l} / \mathrm{h}$, cone gas flow of $50 \mathrm{l} / \mathrm{h}$, capillary voltage of $3.0 \mathrm{kV}$, sample cone voltage of $40 \mathrm{~V}$, extraction cone of $1 \mathrm{eV}$ and a scan range of $50-1,000 \mathrm{~m} / \mathrm{z}$.

Interaction of DL0410 with CYP450s in vitro and in silico. Metabolism of DL0410 in recombinant CYP450s (CYP1A2, CYP2C9, CYP2D6 and CYP3A4) was conducted initially by DL0410 $(10 \mu \mathrm{M})$ in a typical incubation system, containing potassium phosphate buffer (pH 7.4), NADPH-generating system and the appropriate concentration recombinant CYP450s. Following pre-warming at $37^{\circ} \mathrm{C}$ for $5 \mathrm{~min}$, recombinant CYP450s (100 pmol/l) were added and incubated at $37^{\circ} \mathrm{C}$ for $2 \mathrm{~h}$. The reaction was terminated by adding 2 -fold of ACN for protein precipitation and DL0410 extraction. The mixture was centrifuged at $1,204 \mathrm{x} \mathrm{g}$ at room temperature for $10 \mathrm{~min}$ and an aliquot of supernatant was transferred for LC-MS/MS analysis. The CDOCKER protocol in Discovery Studio (DS) 
2016 (Accelrys Software, Inc., San Diego, CA, USA) was utilized in the present study to investigate the binding mode of DL0410 with CYP450s, and the crystal structure of CYP450s were downloaded from Protein Data Bank (PDB; identification no. 3QM4) (24). Prior to using the docking program, the Prepare Protein tool, which is a plugin of DS 2016 was used to perform a series of tasks, including inserting missing atoms in incomplete residues, modeling missing loop regions, deleting alternate conformations, removing waters, standardizing atom names and protonating titratable residues.

Method validation. The LC-MS method for detecting the concentration of DL0410 in the blood and brain samples was validated by examining the specificity and sensitivity, linearity, precision and accuracy, recovery, stability and the matrix effect. The precision and accuracy for DL0410 were evaluated by quality control $(\mathrm{QC})$ samples $(\mathrm{n}=6)$ with low, medium and high concentrations $(15.63,62.50$ and $500 \mathrm{ng} / \mathrm{ml})$ on the same day and 5 independent days. A total of three QC concentration levels in six replicates were used to examine the extraction recovery, by recording the peak response of the plasma/brain tissue and comparing it with the normal samples. The short and long-term freezing and thawing stability of DL0410 in plasma/brain tissue were evaluated by analysis of the QC samples at three concentration levels. The short and long-term stability was tested by storing the samples for $24 \mathrm{~h}$ at room temperature, $4^{\circ} \mathrm{C}$ and $-40^{\circ} \mathrm{C}$ for 4 weeks. The freezing-thawing stability was analyzed following three freeze and thaw cycles, and the matrix effect was additionally examined at three QC concentration levels by comparing the peak area ratio of the neat standard in post-extracted samples to those of neat standard solutions.

Experimental design and sample collection. A total of 90 rats were used for plasma, brain, bile, urine and feces sample collection. To collect the plasma samples, 24 SD rats (12 males and 12 females) were separated into four parallel designed groups at random. The drug was administered orally in groups $1-3(25$, 50 and $100 \mathrm{mg} / \mathrm{kg}$, respectively) and intravenously $(5 \mathrm{mg} / \mathrm{kg})$ in group 4. Each group consisted of six rats (three male and three female rats). The blood samples were collected from the eye venous plexus (25). The blood samples were collected at intervals of $0,0.25,0.33,0.5,0.75,1,1.5,2,4,6,8,12,24,36$ and $48 \mathrm{~h}$ for oral administration, and $0.083,0.25,0.33,0.5,0.75$, $1,1.5,2,4,6,8,12,24,36$ and $48 \mathrm{~h}$ for intravenous administration. Brain samples $(\mathrm{n}=6)$ of $54 \mathrm{SD}$ rats (three males and three females) were collected at $0,0.25,0.75,1,2,4,8,12$ and $24 \mathrm{~h}$ following oral administration of DL0410 $(100 \mathrm{mg} / \mathrm{kg})$. Normal saline was subsequently used to immediately rinse the hippocampus (HIP) and entorhinal cortex (EC), and blotted with filter paper. Normal saline was used to homogenize the accurately weighed tissues, which were subsequently stored at $-40^{\circ} \mathrm{C}$ pending analysis. Rats $(\mathrm{n}=6$; sex ratio $3: 3)$ were anesthetized with ether and the bile duct was cannulated with tubing (Portex Nylon tubing; $0.75 \mathrm{~mm}$ internal diameter; $0.94 \mathrm{~mm}$ external diameter). Bile samples were collected via the bile cannula prior to drug administration as a control and at $0-3$, 3-6, 6-12, 12-24 and 24-36 h following administration. Urine and feces were collected from six rats (sex ratio 3:3). Urine was collected while the rats remained in isolated metabolic cages at $0-2,2-4,4-6,6-8,8-12,12-24,24-48$ and $48-72 \mathrm{~h}$, and the volume was measured. Lastly, fecal samples were collected at 0-12, 12-24, 24-36, 36-48 and 48-72 $\mathrm{h}$. The fecal samples were dried and crushed, and measured for volume. Bile, urine and feces for the metabolite investigation were collected between 2-8 $\mathrm{h}$ following oral administration of $100 \mathrm{mg} / \mathrm{kg}$ DL0410.

Preparation of calibration standards and QC samples. Primary stock solutions of DL0410 and IS were separately prepared by forming a $1 \mathrm{mg} / \mathrm{ml}$ analyte/methanol solution, and stored at $-40^{\circ} \mathrm{C}$. Stock solutions were diluted to working solutions with methanol for use. Corresponding model working solutions were spiked with $100 \mu \mathrm{l}$ blank rat plasma and brain tissue, and subsequently used as QC samples, at concentrations of 7.81 [lower limit of quantification (LLOQ)], $15.63,62.50$ and $500 \mathrm{ng} / \mathrm{ml}$. To construct the plasma and brain sample calibration curves, a series of working standard solution concentrations $(7.81,15.63,31.25,62.50,125,250$, 500 and $1,000 \mathrm{ng} / \mathrm{ml}$ DL0410) were similarly prepared. The seven-point concentration curve of biliary samples, urinary samples and fecal samples were 15.63-1,000, 31.25-2,000 and $31.25-2,000 \mathrm{ng} / \mathrm{ml}$, respectively.

Sample preparation. Rat plasma, brain, bile, urine and fecal samples $(100 \mu \mathrm{l})$ and $10 \mu \mathrm{l}$ of IS solution $(500 \mathrm{ng} / \mathrm{ml})$ were mixed, with $1,000 \mu 1$ ethyl acetate being added to extract the analytes. Following vortexing at room temperature for $5 \mathrm{~min}$, the mixture was centrifuged at $1,304 \mathrm{x} \mathrm{g}$ for $10 \mathrm{~min}$ at room temperature. The supernatant fluid was transferred to another tube and evaporated under a light flow of nitrogen gas, until dry. The residue was reconstituted in $75 \mu \mathrm{l}$ methanol-ACN-water (15:10:75; v/v, containing $0.5 \%$ formic acid) for plasma and brain samples, and $100 \mu \mathrm{l}$ for biliary, urinary and fecal samples. Following centrifugation, the supernatant was injected into the LC-MS system for analysis.

Statistical analysis. DAS 3.0 pharmacokinetic program (Chinese Pharmacology Society, Shanghai, China) software was used to calculate the pharmacokinetic parameters and a non-compartment model analysis was employed. The absolute bioavailability $\left(\mathrm{F}_{\mathrm{abs} \%}\right)$ was calculated as follows (26):

$$
\mathrm{F}_{\mathrm{abs} \%}=\text { AUCpo } \times \text { Div/AUCiv x Dpo x100 }
$$

AUCpo, area under the curve of oral administration; AUCiv, area under the curve of intravenous injection; Dpo, dose of oral administration; Div, dose of intravenous injection.

Standard deviations, accuracy [relative error (RE)] and precision [relative standard deviation (RSD)] were calculated using Microsoft Excel 2010 (Microsoft Corporation, Redmond, WA, USA). Linear regression analysis, plasma concentration time curves and cumulative excretion amount curves were constructed using GraphPad Prism 6 software (GraphPad Software, Inc., La Jolla, CA, USA).

\section{Results}

Validation of LC-MS method. The calibration curves demonstrated good linearity for DL0410 in the 7.81-1,000 ng/ml range for the plasma and brain samples, $15.63-2,000 \mathrm{ng} / \mathrm{ml}$ range for 
Table I. Accuracy and precision of the samples at LLOQ $(7.812 \mathrm{ng} / \mathrm{ml})$ and quality control with high, medium and low concentration $(500,62.5$ and $15.625 \mathrm{ng} / \mathrm{ml}$, respectively; $\mathrm{n}=5)$.

\begin{tabular}{lccccc}
\hline Analyte & $\begin{array}{c}\text { Spiked } \\
\text { concentration, ng/ml }\end{array}$ & $\begin{array}{c}\text { Mean measured } \\
\text { concentration, ng/ml }\end{array}$ & $\begin{array}{c}\text { Relative } \\
\text { error, \% }\end{array}$ & $\begin{array}{c}\text { Intra-day } \\
\text { RSD, \% }\end{array}$ & $\begin{array}{c}\text { Inter-day } \\
\text { RSD, \% }\end{array}$ \\
\hline DL0410 in plasma & 7.81 (LLOQ) & 8.12 & 3.91 & 4.41 & 8.78 \\
& 15.63 & 15.19 & 5.27 & 3.71 & 4.91 \\
& 62.50 & 63.10 & 3.68 & 4.46 & 2.50 \\
DL0410 in brain sample & 500 & 534.20 & 6.84 & 5.62 & 3.95 \\
& 7.81 (LLOQ) & 8.08 & 3.43 & 3.34 & 7.88 \\
& 15.63 & 15.44 & -1.21 & 2.96 & 4.46 \\
& 62.50 & 64.85 & 3.77 & 5.01 & 5.92 \\
& 500 & 514.75 & 2.95 & 2.08 & 7.30 \\
\hline
\end{tabular}

LLOQ, lower limit of quantification; RSD, relative standard deviation.

A a

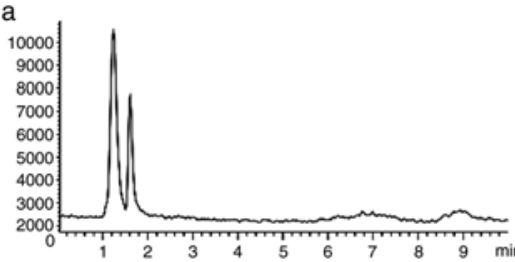

$\mathrm{B}$ a

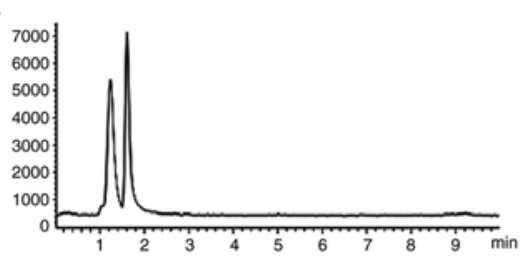

$\mathrm{C}$ a

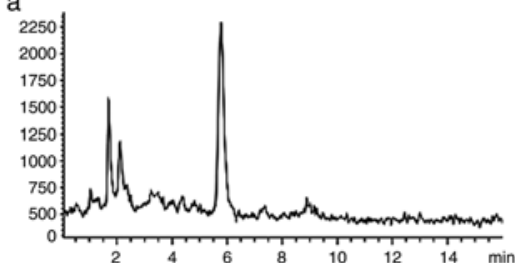

D a

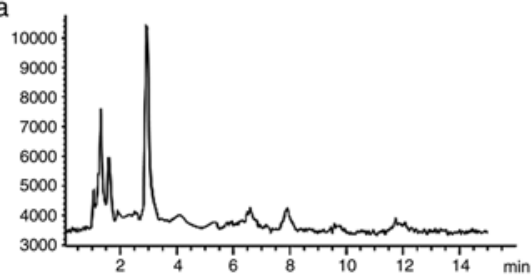

E a

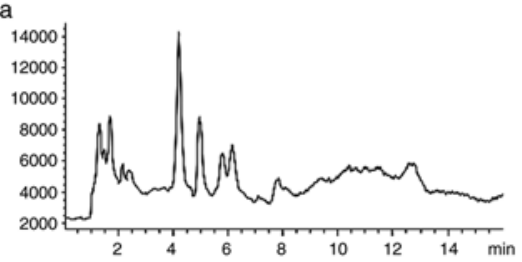

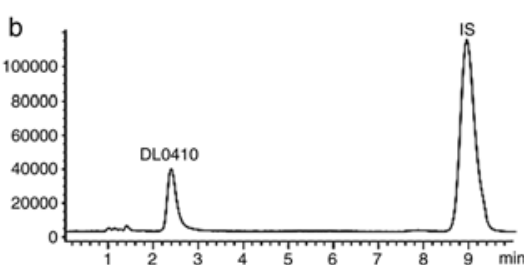
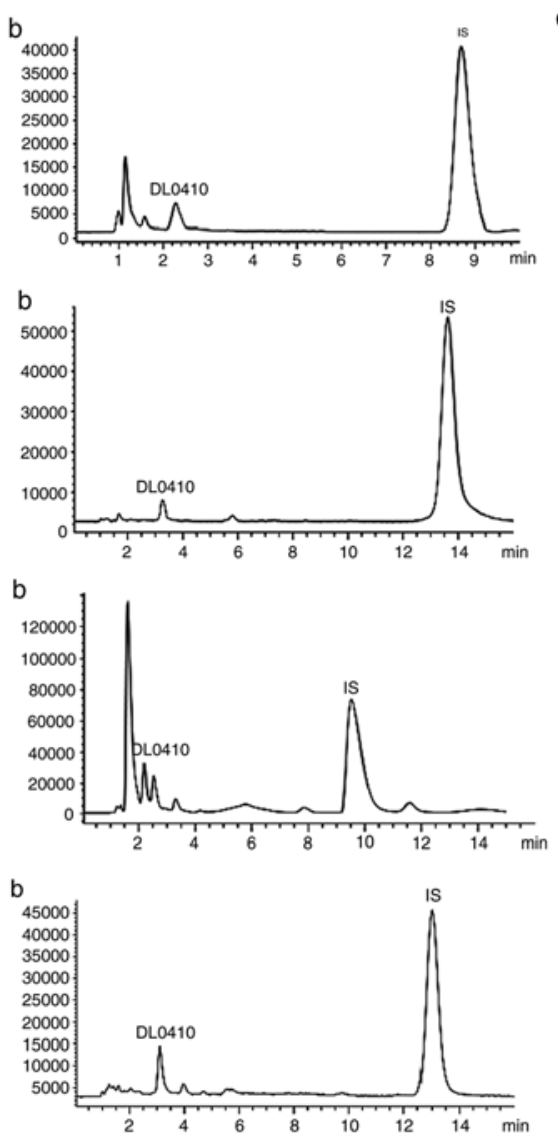
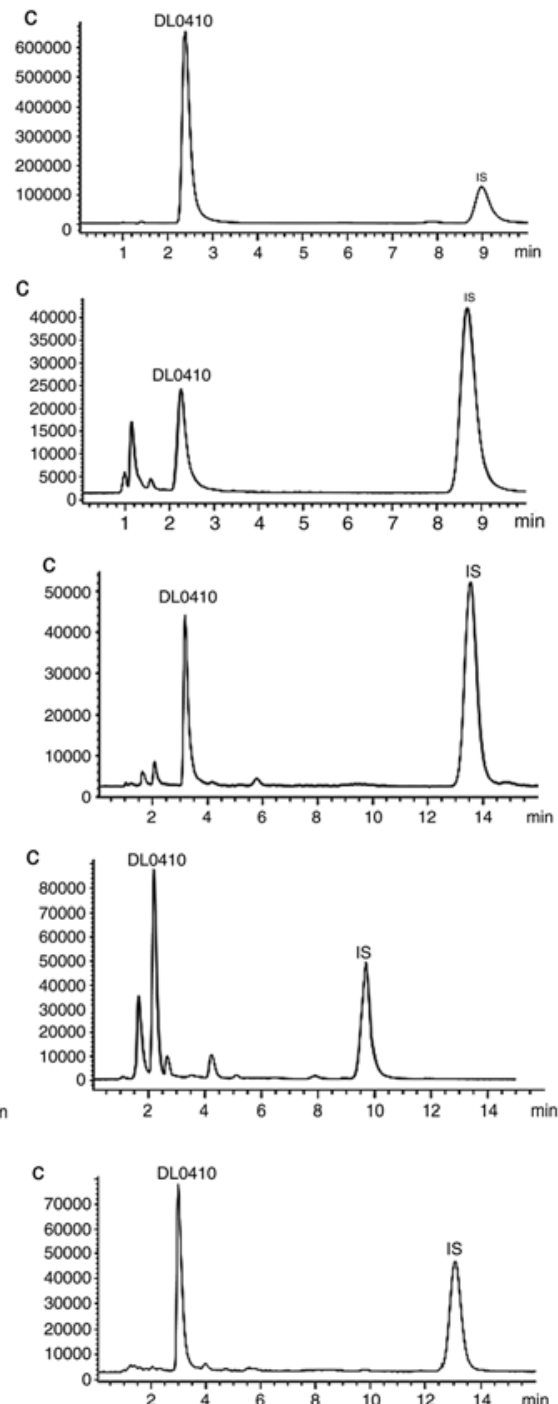

Figure 1. Liquid chromatography-mass spectrometry chromatograms for plasma, brain, bile, urine and fecal samples. Representative liquid chromatography-mass spectrometry chromatograms for (Aa) a blank plasma sample; (Ab) a plasma sample at the LLOQ of $7.812 \mathrm{ng} / \mathrm{ml}$ for DL0410 and (Ac) a plasma sample following oral administration of DL0410 (100 mg/kg). (Ba) Blank brain sample; (Bb) a brain sample at the LLOQ of $7.812 \mathrm{ng} / \mathrm{ml}$ for DL0410 and (Bc) a brain sample following oral administration of DL0410 (100 mg/kg). (Ca) Blank bile sample; (Cb) a bile sample at the LLOQ of $15.625 \mathrm{ng} / \mathrm{ml}$ for DL0410 and (Cc) a bile sample following oral administration of DL0410 (100 mg/kg). (Da) Blank urine sample; (Db) a urine sample at the LLOQ of $31.25 \mathrm{ng} / \mathrm{ml}$ for DL0410; (Dc) a urine sample following oral administration of DL0410 $(100 \mathrm{mg} / \mathrm{kg}$ ). (Ea) Blank fecal sample; (Eb) a fecal sample at the LLOQ of $31.25 \mathrm{ng} / \mathrm{ml}$ for DL0410 and (Ec) a fecal sample following oral administration of DL0410 (100 mg/kg). LLOQ, lower limit of quantification; IS, internal standard. 
Table II. Recoveries and matrix effects of DL0410 in rat plasma and brain samples $(n=5)$.

\begin{tabular}{|c|c|c|c|c|c|}
\hline Analyte & $\begin{array}{c}\text { Spiked } \\
\text { concentration, } \mathrm{ng} / \mathrm{ml}\end{array}$ & Recovery, \% & $\begin{array}{l}\text { Recovery } \\
\text { RSD, \% }\end{array}$ & $\begin{array}{c}\text { Matrix } \\
\text { effects, \% }\end{array}$ & $\begin{array}{c}\text { Matrix } \\
\text { effects RSD, \% }\end{array}$ \\
\hline \multirow[t]{3}{*}{ DL0410 in plasma } & 15.63 & 99.44 & 2.19 & 97.99 & 3.66 \\
\hline & 62.50 & 93.66 & 8.37 & 100.84 & 6.73 \\
\hline & 500 & 105.64 & 2.51 & 105.58 & 1.77 \\
\hline \multirow[t]{3}{*}{ DL0410 in brain sample } & 15.63 & 75.31 & 2.76 & 102.56 & 4.11 \\
\hline & 62.50 & 87.42 & 5.30 & 102.30 & 3.58 \\
\hline & 500 & 90.15 & 2.86 & 93.78 & 2.50 \\
\hline
\end{tabular}

RSD, relative standard deviation.

Table III. Stability of DL0410 in rat plasma and brain samples $(n=5)$.

\begin{tabular}{|c|c|c|c|c|c|}
\hline \multirow[b]{2}{*}{ Condition } & \multirow[b]{2}{*}{$\begin{array}{c}\text { Spiked } \\
\text { concentration, } \mathrm{ng} / \mathrm{ml}\end{array}$} & \multicolumn{2}{|c|}{ DL0410 in plasma } & \multicolumn{2}{|c|}{ DL0410 in brain sample } \\
\hline & & $\begin{array}{c}\text { Measured } \\
\text { concentration, } \mathrm{ng} / \mathrm{ml}\end{array}$ & $\mathrm{RE}$, & $\begin{array}{c}\text { Measured } \\
\text { concentration, }(\mathrm{ng} / \mathrm{ml})\end{array}$ & $\mathrm{RE}, \%$ \\
\hline \multirow[t]{3}{*}{ Three freeze/thaw cycles } & 15.63 & $14.67 \pm 0.74$ & -6.14 & $15.35 \pm 0.76$ & -1.74 \\
\hline & 62.50 & $66.78 \pm 1.01$ & 6.86 & $61.42 \pm 3.80$ & -1.73 \\
\hline & 500 & $500.99 \pm 5.93$ & -0.88 & $498.70 \pm 34.39$ & -1.07 \\
\hline Short-term & 15.63 & $15.37 \pm 0.47$ & -1.61 & $15.434 \pm 0.74$ & -1.27 \\
\hline \multirow[t]{2}{*}{$\left(25^{\circ} \mathrm{C}\right.$ for $\left.4 \mathrm{~h}\right)$} & 62.50 & $64.65 \pm 18.81$ & 3.43 & $61.03 \pm 3.48$ & -2.35 \\
\hline & 500 & $461.97 \pm 16.65$ & -7.61 & $498.70 \pm 13.25$ & -0.26 \\
\hline Autosampler & 15.63 & $15.47 \pm 0.66$ & -1.02 & $15.10 \pm 1.08$ & -3.36 \\
\hline \multirow[t]{2}{*}{$\left(25^{\circ} \mathrm{C}\right.$ for $\left.24 \mathrm{~h}\right)$} & 62.50 & $64.03 \pm 2.15$ & 2.44 & $66.04 \pm 2.87$ & 5.67 \\
\hline & 500 & $491.76 \pm 24.80$ & -1.47 & $467.64 \pm 18.90$ & -6.46 \\
\hline Long-term & 15.63 & $16.70 \pm 0.17$ & 6.92 & $15.70 \pm 0.53$ & 0.49 \\
\hline \multirow[t]{2}{*}{$\left(-40^{\circ} \mathrm{C}\right.$ for 4 weeks $)$} & 62.50 & $60.38 \pm 1.52$ & -3.4 & $61.73 \pm 5.29$ & -1.28 \\
\hline & 500.00 & $526.50 \pm 10.94$ & 5.24 & $489.78 \pm 19.89$ & -2.05 \\
\hline
\end{tabular}

$\mathrm{RE}$, relative error.

the biliary samples, and in the $31.25-2,000 \mathrm{ng} / \mathrm{ml}$ range for the urinary and fecal samples. The correlation coefficients (r) of DL0410 were 0.9998 in the plasma samples, 0.9999 in the brain samples, 0.9948 in the biliary samples, 0.9996 in the urinary samples and 0.9964 in the fecal samples. LLOQ of plasma and brain samples was acquired with sufficient precision and accuracy (Table I) (25).

No endogenous interference with DL0410 or IS was observed. Additionally, good separation was achieved for DL0410 and IS. The representative chromatogram patterns of the blank samples, samples at LLOQ and samples following oral administration are presented in Fig. 1.

The RE and RSD values $<10 \%$ (27) were within the tolerated limits for the QCs with high, medium and low concentrations (Table I). The mean recoveries and matrix effects for these three concentrations are presented in Table II. The RE determined from all of the stability tests were within $\pm 6.92 \%$ of each other (Table III). The results demonstrated that the accuracy, precision, recovery and stability tests met the criteria for quantitative determination in biological samples (28).
Method application in a pharmacokinetic study. The established LC-MS method was successfully applied to measure the DL0410 concentration in the rat plasma samples following oral and intravenous administration. The time profiles of the plasma concentration of DL0410 following oral administration at 25,50 and $100 \mathrm{mg} / \mathrm{kg}$ and following intravenous administration at a dose of $5 \mathrm{mg} / \mathrm{kg}$ are presented in Fig. 2 . The primary plasma pharmacokinetic data are summarized in Table IV. For oral administration, during the $45 \mathrm{~min}$ following dose administration, the DL0410 plasma concentrations increased rapidly to maximum serum concentration $\left(\mathrm{C}_{\max } ; 195.79 \pm 46.76 \mathrm{ng} / \mathrm{ml}\right.$ for $100 \mathrm{mg} / \mathrm{kg} ; 56.15 \pm 4.01 \mathrm{ng} / \mathrm{ml}$ for $50 \mathrm{mg} / \mathrm{kg}$; and $21.48 \pm 3.46 \mathrm{ng} / \mathrm{ml}$ for $25 \mathrm{mg} / \mathrm{kg}$; Fig. 2A). Specifically, there were two peaks observed in Fig. 2. Following intravenous administration, the plasma concentration of DL0410 decreased (Fig. 2B). The fold increase in oral dosage ( $25 \mathrm{vs.} 50 \mathrm{vs.} 100 \mathrm{mg} / \mathrm{kg}$ ) did not lead to a fold-increase in $\mathrm{AUC}_{0-\mathrm{t}}(978.14 \pm 229.53 \mu \mathrm{g} / 1 \mathrm{x}$ h vs. $238.87 \pm 63.03 \mu \mathrm{g} / \mathrm{l}$ $\mathrm{x}$ h vs. 135.40 $\pm 22.41 \mu \mathrm{g} / \mathrm{l} \mathrm{x}$ h; Table IV). The data demonstrated that $\mathrm{C}_{\max }$ and $\mathrm{AUC}_{0-\mathrm{t}}$ of DL0410 did not increase in a 
Table IV. Pharmacokinetic parameters of DL0410 following intravenous $(5 \mathrm{mg} / \mathrm{kg})$ and oral $(100,50 \mathrm{and} 25 \mathrm{mg} / \mathrm{kg})$ administration in rats $(\mathrm{n}=6)$.

\begin{tabular}{|c|c|c|c|c|c|}
\hline \multirow[b]{2}{*}{ Parameter } & \multirow[b]{2}{*}{ Unit } & \multirow{2}{*}{$\begin{array}{l}\text { Intravenous dose } \\
55 \mathrm{mg} / \mathrm{kg}\end{array}$} & \multicolumn{3}{|c|}{ Oral dose } \\
\hline & & & $100 \mathrm{mg} / \mathrm{kg}$ & $50 \mathrm{mg} / \mathrm{kg}$ & $25 \mathrm{mg} / \mathrm{kg}$ \\
\hline $\mathrm{AUC}_{(0-\mathrm{t})}$ & $\mu \mathrm{g} / 1 \mathrm{x} \mathrm{h}$ & $251.10 \pm 183.05$ & $978.14 \pm 229.53$ & $238.87 \pm 63.03$ & $135.40 \pm 22.41$ \\
\hline $\mathrm{MRT}_{(0-\mathrm{t})}$ & $\mathrm{h}$ & $19.91 \pm 1.88$ & $12.17 \pm 1.45$ & $6.73 \pm 1.20$ & $4.51 \pm 0.89$ \\
\hline $\mathrm{t}_{1 / 2 \mathrm{z}}$ & $\mathrm{h}$ & $0.08 \pm 0.02$ & $8.23 \pm 4.02$ & $7.54 \pm 2.97$ & $6.05 \pm 0.34$ \\
\hline $\mathrm{T}_{\max }$ & $\mathrm{h}$ & 0.03 & $0.75 \pm 0.27$ & $0.65 \pm 0.23$ & $0.63 \pm 0.12$ \\
\hline $\mathrm{C}_{\max }$ & $\mu \mathrm{g} / 1$ & $724.85 \pm 85.92$ & $195.79 \pm 46.76$ & $56.15 \pm 4.01$ & $21.48 \pm 3.46$ \\
\hline $\mathrm{F}_{\mathrm{abs} \%}$ & & - & $24.18 \pm 0.03$ & $12.19 \pm 0.03$ & $10.78 \pm 0.02$ \\
\hline
\end{tabular}

AUC, area under the curve; MRT, mean residence time; $\mathrm{t}_{1 / 2}$, half-life; $\mathrm{T}_{\max }$, time to maximum concentration; $\mathrm{C}_{\max }$, maximum serum concentration; $\mathrm{F}_{\mathrm{abs} \%}$, absolute bioavailability.
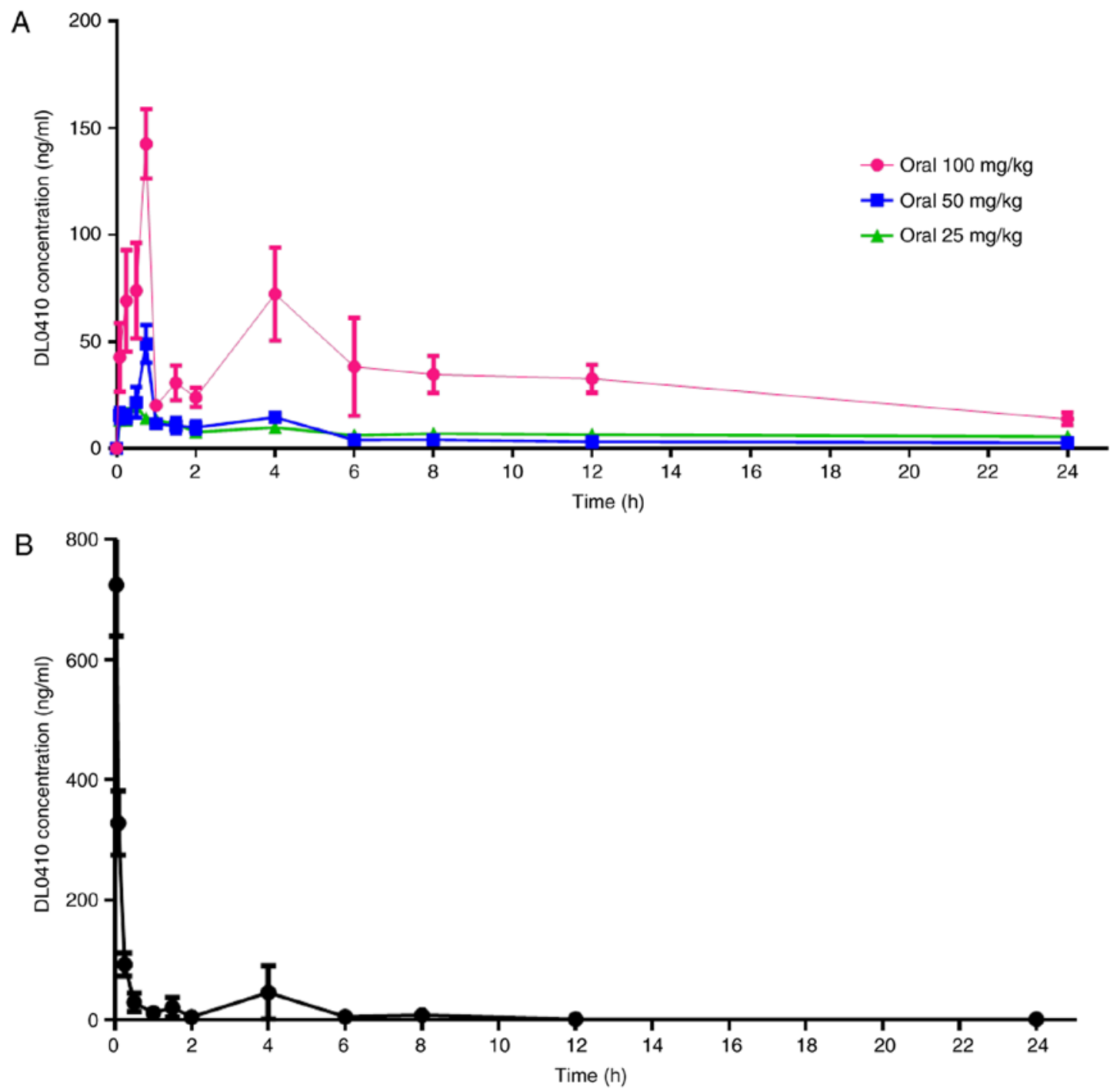

Figure 2. Mean plasma concentration-time profile of DL0410 following administration at different doses. Mean plasma concentration-time profile of DL0410 following oral administration at dose of (A) 25,50 and $100 \mathrm{mg} / \mathrm{kg}$ and following intravenous administration at dose of (B) $5 \mathrm{mg} / \mathrm{kg}$, to rats. Data are presented as the mean \pm standard deviation. $\mathrm{n}=6$.

dose-dependent manner at doses between 25 and $100 \mathrm{mg} / \mathrm{kg}$. The half-life $\left(t_{1 / 2}\right)$ extended with the increasing dosage between
6.05 and $8.23 \mathrm{~h}$. The oral bioavailability of DL0410 in rats was 10.78 and $12.19 \%$ at the low and medium doses (25 and 


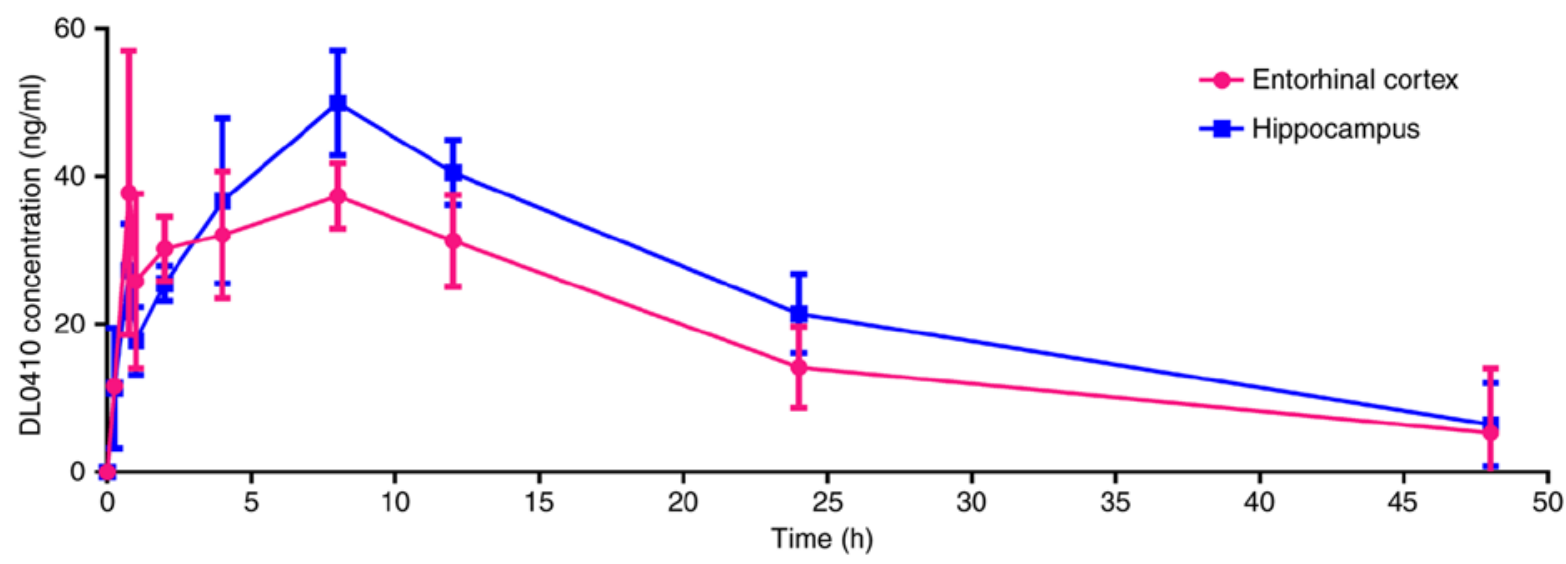

Figure 3. Mean entorhinal cortex and hippocampus concentration-time profile of DL0410 following oral administration at dose of $100 \mathrm{mg} / \mathrm{kg}$ to rats. Data are presented as the mean \pm standard deviation. $n=6$.

A

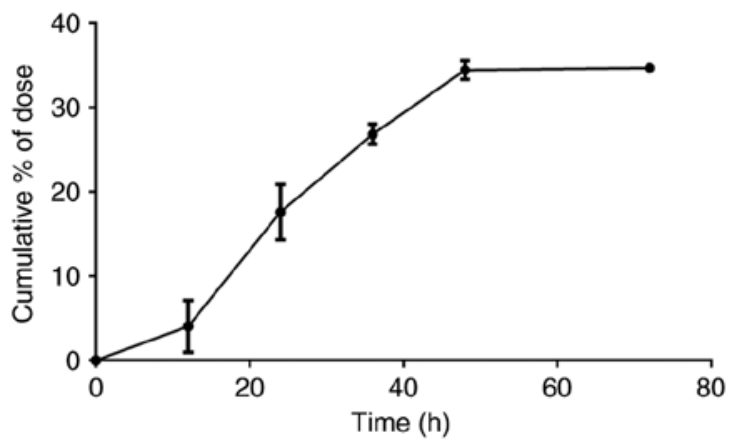

B

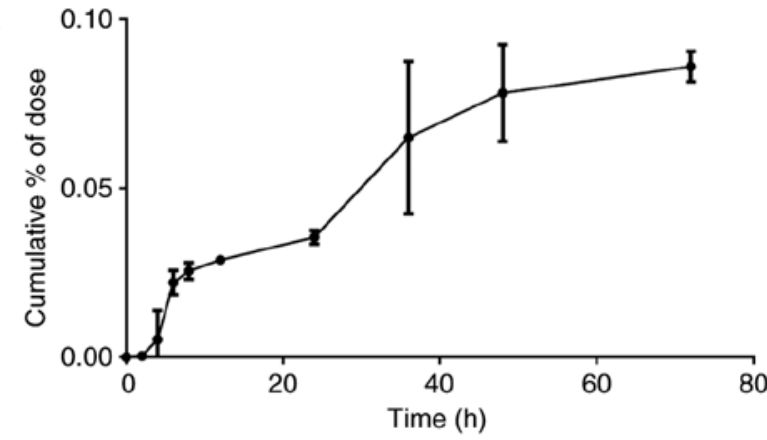

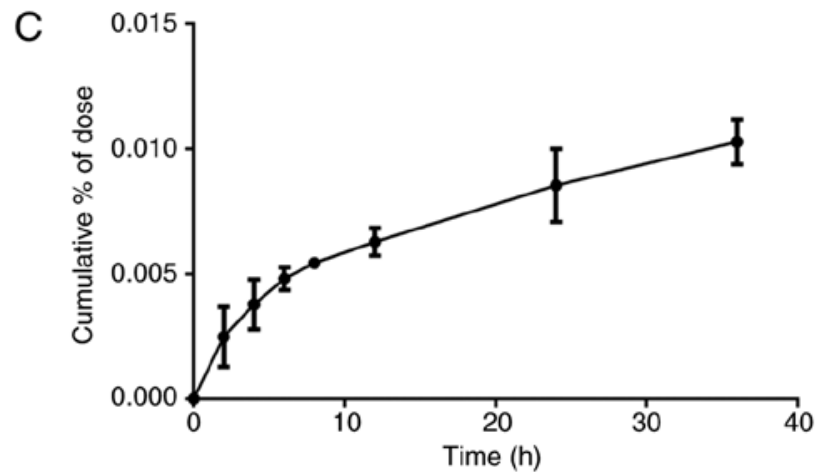

Figure 4. Excretion of DL0410 in the feces, urine and bile of rats. Excretion of DL0410 in (A) feces, (B) urine and (C) bile of rats following a single oral dose of DL0410 at $100 \mathrm{mg} / \mathrm{kg}$. Data are presented as the mean \pm standard deviation. $\mathrm{n}=6$.

$50 \mathrm{mg} / \mathrm{kg}$ ), respectively, and increased to $24.18 \%$ at $100 \mathrm{mg} / \mathrm{kg}$. The concentration-time profile of DL0410 in the EC and HIP following oral administration at a dose of $100 \mathrm{mg} / \mathrm{kg}$ to rats is presented in Fig. 3. Time to maximum concentration $\left(\mathrm{T}_{\max }\right)$ of DL0410 in the two regions was $\sim 6 \mathrm{~h}$ and the values of $\mathrm{C}_{\max }$ were $50.27 \pm 6.92 \mathrm{ng} / \mathrm{ml}$ and $46.23 \pm 13.17 \mathrm{ng} / \mathrm{ml}$ for HIP and EC, respectively.

Excretion study. The cumulative DL0410 excretion results in rat bile, urine and feces, following oral administration with DL0410 $(100 \mathrm{mg} / \mathrm{kg})$, are presented in Fig. 4. The cumulative urinary excretion of DL0410 was very small, only $0.086 \%$ of the dose in $72 \mathrm{~h}$. The accumulated excretion of DL0410 in bile for $36 \mathrm{~h}$ was even lower, with $0.010 \%$ of the dose being excreted. The cumulative fecal excretion of DL0410 accounted for $34.71 \%$.
Metabolism of DL0410 identified in vivo and in vitro. Following a full scan and subsequent product ion scan identification of the bile, urine and fecal samples following DL0410 administration, two common DL0410 metabolites at $\mathrm{m} / \mathrm{z} 435.3231$ and $\mathrm{m} / \mathrm{z} 437.3397$ were identified (Fig. 5). Recombinant human CYP450 enzymes (CYP1A2, CYP 2C9, CYP2D6 and CYP3A4) were used to evaluate the contribution of CYP450 enzymes to the reduction reaction. As a result, CYP2D6 was identified to be involved in the reduction of the carbonyl group.

Docking study of CYP2D6 and DL0410. The molecular docking assessment between CYP2D6 and DL0410 was performed using the CDOCKER module in the DS 2016 package. The crystal structure of CYP2D6 was obtained from the PDB (identification no. 3QM4) (26). The water molecules 

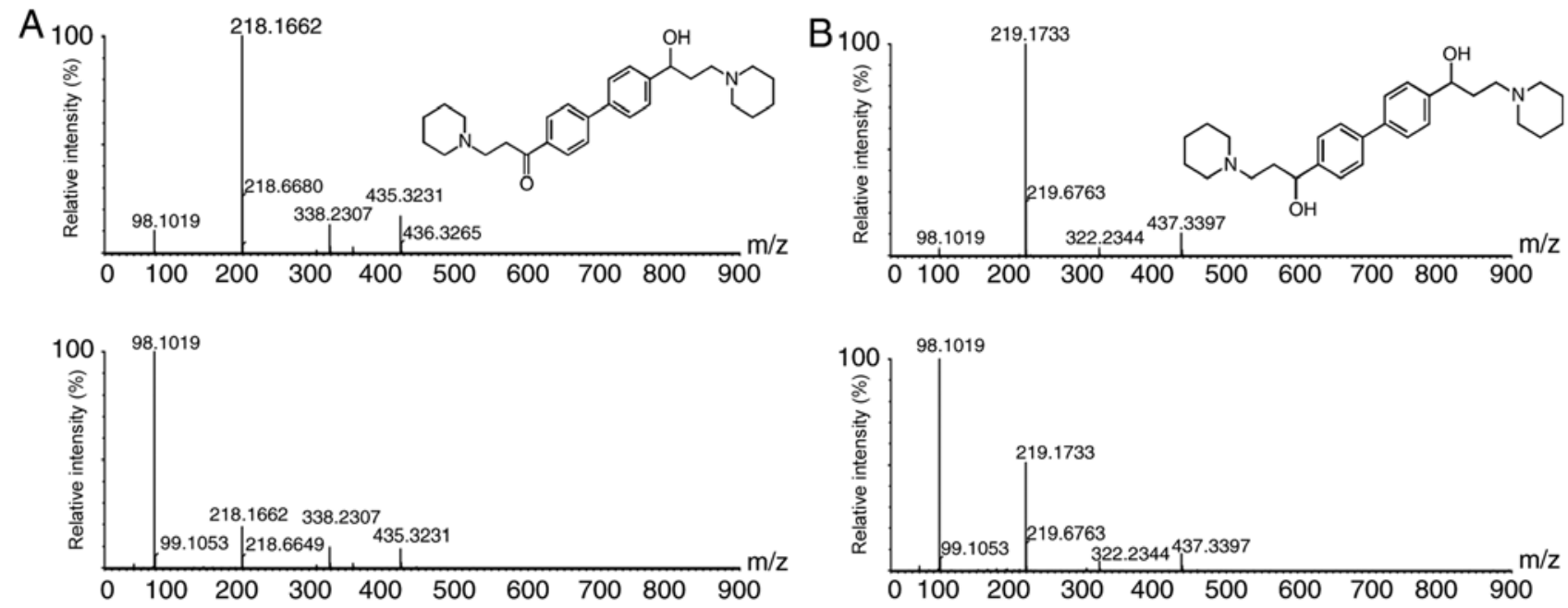

Figure 5. Full scan, product ion scan and proposed structures of DL0410 metabolites. (A) Full scan, product ion scan and proposed structure of M1, at m/z 435.3231. (B) Full scan, product ion scan and proposed structure of M2, at $\mathrm{m} / \mathrm{z} 437.3397$.
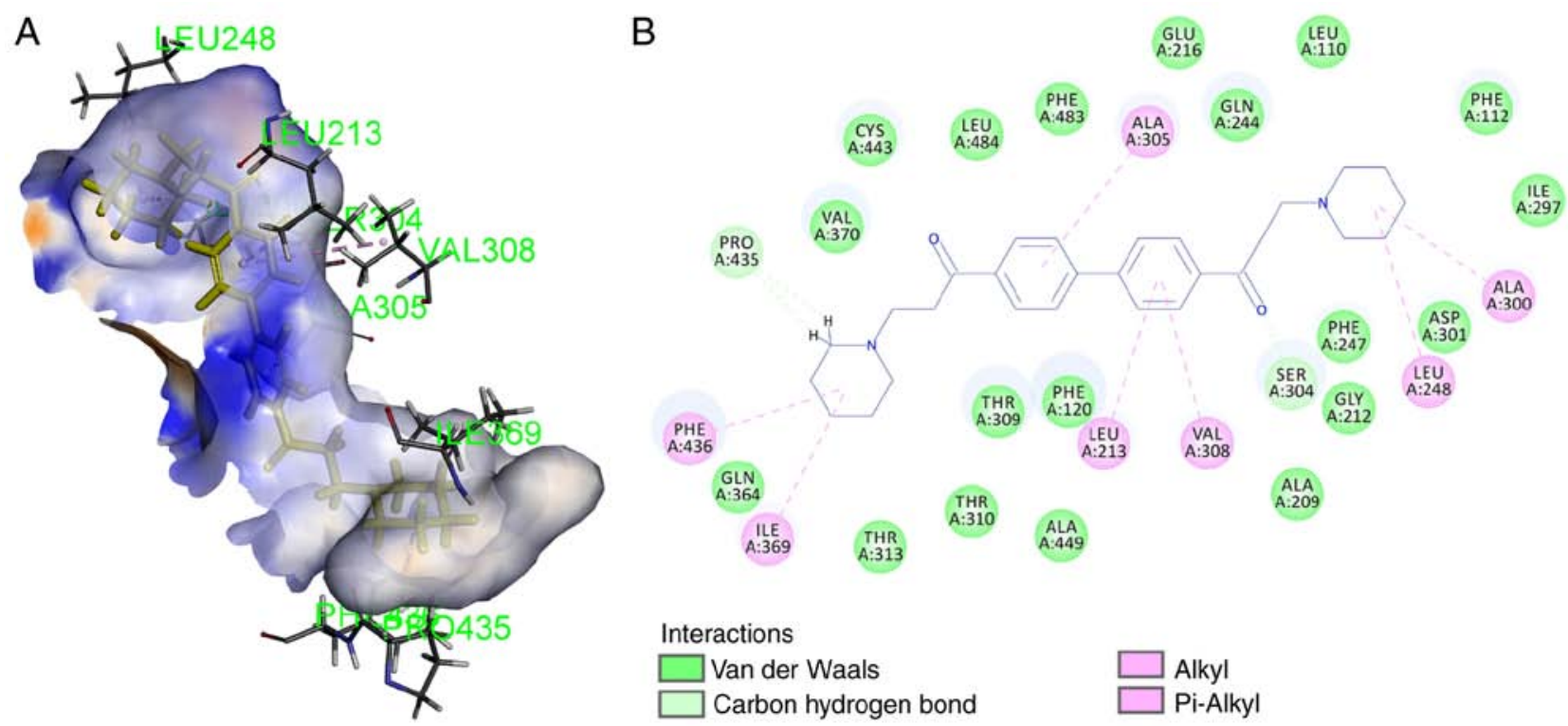

Figure 6. Interaction of DL0410 with CYP2D6. (A) Computational model of DL0410 docked in the active pocket of CYP2D6. (B) Interaction residues of CYP2D6 with DL0410. The interaction of DL0410 and CYP2D6 primarily refers to hydrogen bonds and hydrophobic attraction. The interacting residues include ILE213, LEU248, ALA200, VAL308, ILE369, PRO435 and PHE436.

in the protein were removed, and the protein was prepared by adding hydrogen and correcting the incomplete residues using the Prepare Protein tool; the protein was subsequently refined. The structure of DL0410 was prepared and was followed by hydrogen addition, conversion into a 3D structure, $\mathrm{pH}$ based ionization and charge neutralization. The binding site of CYP2D6 was defined by the ligand prinomastat. To validate the docking approach for the protein structure used, prinomastat was redocked to the active site. The root-mean-square deviation was 0.6229 , which indicated the reliability of this docking model. The results demonstrated that DL0410 has a moderate interaction with CYP2D6 by residues of ILE213, LEU248, ALA200, VAL308, ILE369, PRO435 and PHE436 (Fig. 6). -CDOCKER ENERGY and -CDOCKER INTERACTION ENERGY (a higher value indicates a more favorable binding) were 24.3048 and 59.4411, respectively, which suggests DL0410 has a good affinity with CYP2D6 in silico.

\section{Discussion}

DL0410, a novel cholinesterase inhibitor and H3R antagonist, is currently under preclinical development for use in AD treatment. It is crucial to investigate the pharmacokinetic profile of DL0410 for its demonstrated effectiveness in AD treatment. The present study aimed to evaluate the bioavailability and dose proportionality of DL0410 in rats with a validated method of LC-MS.

Following oral and intravenous administration of DL0410, respectively, pharmacokinetic parameters were acquired. The 
results demonstrated that DL0410 exhibited a fast phase of absorption, reaching $\mathrm{C}_{\max }$ at $\mathrm{T}_{\max }$ of nearly 45 min following the three orally administered doses. There were double peaks in the concentration-time profiles of oral administration of DL0410. The possible mechanisms are primarily associated with enterohepatic circulation, gastric emptying delay, the difference of absorption in various intestinal segments and recirculation (29). Nevertheless, $\mathrm{AUC}_{0-\mathrm{t}}$ values of these three DL0410 dosages were not proportionately increased. Furthermore, the $t_{1 / 2}$ extended with the increasing dosage. Therefore, the results supported non-linear plasma pharmacokinetics of DL0410 across the investigated dosage range in rats. This is possibly due to the saturability of drug metabolic enzymes and transporters. Therefore, $\mathrm{t}_{1 / 2}$ and other pharmacokinetic parameters are no longer constant and $\mathrm{AUC}$ and $\mathrm{C}_{\max }$ are not proportionately increased (30).

Oral DL0410 demonstrated a low level of bioavailability, which is a result of a number of factors, including low permeability, first-pass DL0410 metabolism in the liver, small and large intestinal tracts in addition to low aqueous solubility. Whether DL0410 was able to distribute into the EC in addition to the HIP, which are the most important brain regions for learning and memory, was additionally assessed. The detectable level in the brain demonstrated that DL0410 was able to cross the blood-brain barrier and disperse into the two regions.

The cumulative excretion percentages in urine, feces and bile following oral administration were evaluated. Fecal excretion was the dominant route of elimination for DL0410. The marked difference in excretion levels may be attributed to the low oral bioavailability. DL0410 is poorly absorbed into blood and is instead quickly excreted through the feces. Furthermore, the present study suggested that DL0410 was excreted primarily as metabolites. Based on the results from the present study on rat bile, urine and fecal metabolites of DL0410 following oral administration, the common metabolites at $\mathrm{m} / \mathrm{z} 435.3231$ and $\mathrm{m} / \mathrm{z} 437.3397$ were assigned to carbonyl reduction metabolites. CYP2D6 was identified for the involvement of this reduction reaction in vitro and in silico.

In conclusion, a rapid, highly selective and reliable LC-MS method for the determination of DL0410 in biological matrices was developed and applied to investigate the pharmacokinetics, brain, distribution and excretion of DL0410 in rats. Furthermore, metabolism of DL0410 in urine was identified by UPLC-Q-TOF-MS. The present results provide useful insight for the continued evaluation of DL0410 as a therapeutic agent for AD.

\section{Acknowledgements}

Not applicable.

\section{Funding}

The present study was financially supported by grants from the Research Special Fund for the Public Welfare Industry of Health (grant no. 200802041), and the National Great Science and Technology Projects (grant nos. 2013ZX09402203 and 2014ZX09507003002).

\section{Availability of data and materials}

All data generated or analyzed during this study are included in this published article.

\section{Authors' contributions}

AL and GD designed the experiment and revised the manuscript. XP, YZ, JS and DK performed the experiments. SW and LW acquired the data. XP analyzed the data. All authors read and approved the final manuscript.

\section{Ethics approval and consent to participate}

All experimental protocols involving Sprague-Dawley rats were reviewed and approved by the animal experimentation center of the Institute of Materia Medica, Chinese Academy of Medical Sciences (Beijing, China).

\section{Patient consent for publication}

Not applicable.

\section{Competing interests}

The authors declare that they have no competing interests.

\section{References}

1. Abdalla A: Tau protein as a target for Alzheimer's disease management. Saudi Pharm J 23: 405-406, 2015.

2. Mucke L: Neuroscience: Alzheimer's disease. Nature 461: 895-897, 2009.

3. Tayeb HO, Yang HD, Price BH and Tarazi FI: Pharmacotherapies for Alzheimer's disease: Beyond cholinesterase inhibitors. Pharmacol Ther 134: 8-25, 2012.

4. Martinelli-Boneschi F, Giacalone G, Magnani G, Biella G, Coppi E, Santangelo R, Brambilla P, Esposito F, Lupoli S, Clerici F, et al: Pharmacogenomics in Alzheimer's disease: A genome-wide association study of response to cholinesterase inhibitors. Neurobiol Aging 34: 1711.e7-13, 2013.

5. Citron M: Alzheimer's disease: Strategies for disease modification. Nat Rev Drug Discov 9: 387-398, 2010.

6. Mushtaq G, Greig NH, Khan JA and Kamal MA: Status of acetylcholinesterase and butyrylcholinesterase in Alzheimer's disease and type 2 diabetes mellitus. CNS Neurol Disord Drug Targets 13: 1432-1439, 2014.

7. Ferreira-Vieira TH, Guimaraes IM, Silva FR and Ribeiro FM: Alzheimer's disease: Targeting the cholinergic system. Curr Neuropharmacol 14: 101-115, 2016.

8. Deb PK, Sharma A, Piplani P and Akkinepally RR: Molecular docking and receptor-specific 3D-QSAR studies of acetylcholinesterase inhibitors. Mol Divers 16: 803-823, 2012.

9. Silman I and Sussman JL: Acetylcholinesterase: How is structure related to function? Chem Biol Interact 175: 3-10, 2008.

10. Decroocq C, Stauffert F, Pamlard O, Oulaïdi F, Gallienne E, Martin OR, Guillou C and Compain P: Iminosugars as a new class of cholinesterase inhibitors. Bioorg Med Chem Lett 25: 830-833, 2015.

11. Saeed A, Mahesar PA, Zaib S, Khan MS, Matin A, Shahid M and Iqbal J: Synthesis, cytotoxicity and molecular modelling studies of new phenylcinnamide derivatives as potent inhibitors of cholinesterases. Eur J Med Chem 78: 43-53, 2014.

12. Krátký M, Štěpánková Š , Vorčáková $K$ and Vinšová J: Salicylanilide diethyl phosphates as cholinesterases inhibitors. Bioorg Chem 58: 48-52, 2015.

13. Tao LX, Huang XT, Chen YT, Tang XC and Zhang HY: Acetylcholinesterase-independent protective effects of huperzine A against iron overload-induced oxidative damage and aberrant iron metabolism signaling in rat cortical neurons. Acta Pharmacol Sin 37: 1391-1400, 2016. 
14. Zhou D, Zhou W, Song JK, Feng ZY, Yang RY, Wu S, Wang L, Liu AL and Du GH: DL0410, a novel dual cholinesterase inhibitor, protects mouse brains against $\mathrm{A} \beta$-induced neuronal damage via the Akt/JNK signaling pathway. Acta Pharmacol Sin 37: 1401-1412, 2016.

15. Yang RY, Zhao G, Wang DM, Pang XC, Wang SB, Fang JS, Li C, Liu AL, Wu S and Du GH: DL0410 can reverse cognitive impairment, synaptic loss and reduce plaque load in APP/PS1 transgenic mice. Pharmacol Biochem Behav 139: 15-26, 2015.

16. Lian W, Fang J, Xu L, Zhou W, Kang D, Xiong W, Jia H, Liu AL and Du GH: DL0410 ameliorates memory and cognitive impairments induced by scopolamine via increasing cholinergic neurotransmission in mice. Molecules 22: pii: E410, 2017.

17. Fang J, Yang R, Gao L, Zhou D, Yang S, Liu AL and Du GH: Predictions of BuChE inhibitors using support vector machine and naive bayesian classification techniques in drug discovery. J Chem Inf Model 53: 3009-3020, 2013.

18. Lian W, Jia H, Xu L, Zhou W, Kang D, Liu A and Du G: Multi-protection of DL0410 in ameliorating cognitive defects in D-galactose induced aging mice. Front Aging Neurosci 9: 409, 2017.

19. Clapham J and Kilpatrick GJ: Histamine $\mathrm{H} 3$ receptors modulate the release of $[3 \mathrm{H}]$-acetylcholine from slices of rat entorhinal cortex: Evidence for the possible existence of $\mathrm{H} 3$ receptor subtypes. Br J Pharmacol 107: 919-923, 1992.

20. Arrang JM, Garbarg M and Schwartz JC: Auto-inhibition of brain histamine release mediated by a novel class (H3) of histamine receptor. Nature 302: 832-837, 1983.

21. Blandina P, Giorgetti M, Bartolini L, Cecchi M, Timmerman H Leurs R, Pepeu G and Giovannini MG: Inhibition of cortical acetylcholine release and cognitive performance by histamine H3 receptor activation in rats. Br J Pharmacol 119: 1656-1664, 1996.

22. Bongers G, Bakker RA and Leurs R: Molecular aspects of the histamine H3 receptor. Biochem Pharmacol 73: 1195-1204, 2007.
23. Fang J, Li Y, Liu R, Pang X, Li C, Yang R, He Y, Lian W, Liu AL and Du GH: Discovery of multitarget-directed ligands against Alzheimer's disease through systematic prediction of chemical-protein interactions. J Chem Inf Model 55: 149-164, 2015.

24. Wang A, Savas U, Hsu MH, Stout CD and Johnson EF: Crystal structure of human cytochrome P450 2D6 with prinomastat bound. J Biol Chem 287: 10834-10843, 2012.

25. Zhang D, Huang C, Xin W, Ma X, Zhang W, Zhang T and Du G: Preclinical pharmacokinetic evaluation and metabolites identification of methyl salicylate-2-O- $\beta$-d-lactoside in rats using LC-MS/MS and Q-TOF-MS methods. J Pharm Biomed Anal 109: 1-10, 2015.

26. Tian S, He G, Song J, Wang S, Xin W, Zhang D and Du G: Pharmacokinetic study of baicalein after oral administration in monkeys. Fitoterapia 83: 532-540, 2012.

27. Bressolle F, Bromet-Petit M and Audran M: Validation of liquid chromatographic and gas chromatographic methods. Applications to pharmacokinetics. J Chromatogr B Biomed Appl 686: 3-10, 1996.

28. Xie X, Li Y, Gao D, Zhang Y and Ren Y: Quantitative determination of euphol in rat plasma by LC-MS/MS and its application to a pharmacokinetic study. Biomed Chromatogr 28: 1229-1234, 2014.

29. Godfrey KR, Arundel PA, Dong Z and Bryant R: Modelling the double peak phenomenon in pharmacokinetics. Comput Methods Programs Biomed 104: 62-69, 2011.

30. Yang QJ, Si L, Tang H, Sveigaard HH, Chow EC and Pang KS: PBPK modeling to unravel nonlinear pharmacokinetics of verapamil to estimate the fractional clearance for verapamil $\mathrm{N}$-demethylation in the recirculating rat liver preparation. Drug Metab Dispos 43: 631-645, 2015.

(i) (9) This work is licensed under a Creative Commons Attribution-NonCommercial-NoDerivatives 4.0 International (CC BY-NC-ND 4.0) License. 